\section{Hirschsprung's disease, distinctive facies, and microcephaly}

SIR,

I read with interest the report by Hurst $e t a l^{1}$ in the July issue of the Journal of three children with Hirschsprung's disease, distinctive facies, and microcephaly. The two sibs and an unrelated child were matched by the London Dysmorphology Database and presented as a new syndrome. There was no discussion of similar case reports.

The POSSUM syndrome information system ${ }^{2}$ lists 10 syndromes with Hirschsprung's disease. ${ }^{3-11}$ Eight of the syndromes could be quickly dismissed on the basis of associated findings. The sibs reported by Goldberg and Shprintzen ${ }^{3}$ had the same facial appearance and common features. I believe that this is the same syndrome. Goldberg and Shprintzen ${ }^{3}$ had also proposed this to be of recessive inheritance and the result of an error in neural crest development. Although the case of Brunoni et al $l^{5}$ shares some of the same features it is likely to be a different condition. The features of the five cases from Goldberg and Hurst are listed in the table together with the features of the case reported by Brunoni.

All five patients had Hirschsprung's disease, a distinctive facies, mental retardation, microcephaly, and short stature. The facies was characterised by dense eyebrows, apparent hypertelorism, large nose with broad nasal root, relative prognathism, and anteverted, 'bat' ears. Similar brain CT scan abnormalities were present in four of the patients. Iris colobomata are reported in only one of the sibs and the third patient reported by Hurst et al. Submucous cleft palate was seen in the sibs of Goldberg's report. It would be desirable to review Goldberg's patients for ocular colobomata and Hurst's patients for submucous cleft palate. Goldberg's patients had a spastic gait and neonatal hypotonia; the third case in Hurst's report had spasticity.

Although the karyotypes in the three patients tested were reported to be normal, it is of interest that a similar pattern of features, including Hirschsprung's disease, developmental delay, and coloboma of the iris, was reported in a patient with de novo interstitial deletion of $2 \mathrm{p} 22$ and reciprocal

TABLE Phenotypic features of Hirschsprung's disease, distinctive facies, and microcephaly.

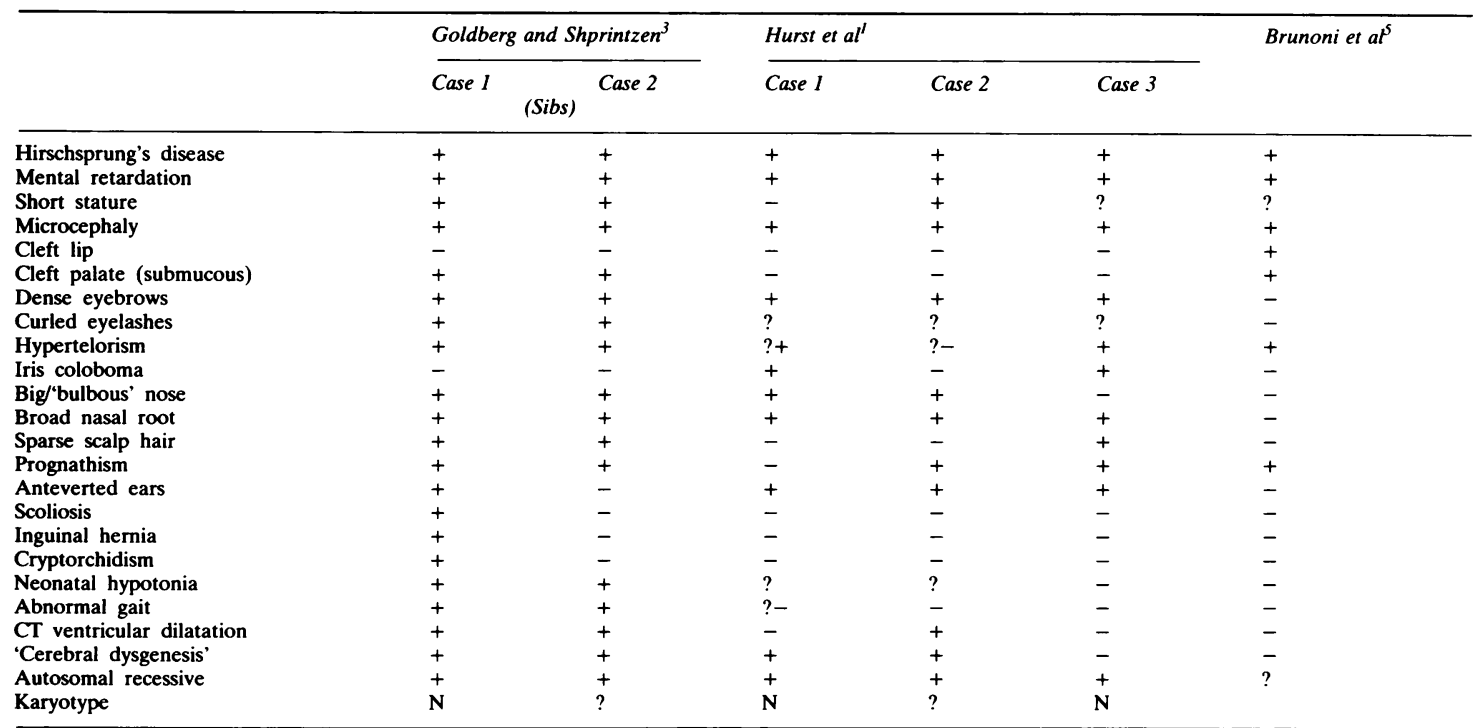


translocation $(3 ; 7)(\mathrm{p} 21 ; \mathrm{q} 22) .^{12}$ Review of karyotypes with high resolution banding may be of value.

Agnes Bankier The Murdoch Institute, Royal Children's Hospital, Flemington Road, Parkville, Victoria 3052, Australia.

\section{References}

${ }^{1}$ Hurst JA, Markiewicz M, Kumar D, Brett EM. Unknown syndrome. Hirschsprung's disease, microcephaly, and iris coloboma: a new syndrome of defective neuronal migration. $J$ Med Genet 1988;25:494-500.

2 POSSUM System. Pictures of standard syndromes and undiagnosed malformation(s). Australia: Murdoch Institute and Computer Power Group, 1987.

${ }^{3}$ Goldberg RB, Shprintzen RJ. Hirschsprung megacolon and cleft palate in two sibs. J Craniofac Genet Dev Biol 1981;1:185-9.

4 Branski D, Dennis NR, Neale JM, Brooks LJ. Hirschsprung's disease and Waardenburg's syndrome. Pediatrics 1979;63:803-5.
${ }^{5}$ Brunoni D, Joffe R, Farah LMS, Cunha AJB. Hirschsprung megacolon, cleft lip and palate, mental retardation and minor congenital malformations. J Clin Dysmorphol 1983;1:20-2.

${ }^{6}$ Curry CJR, Carey JC, Holland JS, et al. Smith-Lemli-Opitz syndrome-type II: multiple congenital anomalies with male pseudohermaphroditism and frequent early lethality. Am J Med Genet 1987;26:45-57.

${ }^{7}$ Laurence KM. Hirschsprung disease with ulnar polydactyly, polysyndactyly of the big toes and VSD. J Med Genet 1975;12: 334-8.

${ }^{8}$ Reynolds JF, Barber JC, Alford BA, Chandler JG, Kelly TEK. Familial Hirschsprung's disease and type D brachydactyly: a report of four affected males in two generations. Pediatrics 1983;71:246-9.

${ }^{9}$ Santos H, Mateus J, Leal M. Hirschsprung disease associated with polydactyly, unilateral renal agenesis, hypertelorism and congenital deafness: a new autosomal recessive syndrome. $J$ Med Genet 1988;25:204-8.

10 Toriello HV, Komar K, Lawrence C, Higgins JV, Waterman DF. Macrocephaly, Hirschsprung's disease, brachydactyly, vertebral defects and other minor anomalies. Dysmorphol Clin Genet 1988;1:155-7.

1 Weinberg AG, Currarino G, Besserman AM. Hirschsprung's disease and congenital deafness, familial association. Hum Genet 1977;38:157-61

12 Webb GC, Keith CG, Campbell NT. Concurrent de novo interstitial deletion of band 2 p22 and reciprocal translocation (3;7)(p21;q22). J Med Genet 1988;25:125-7. 